\title{
Effects of Cooking and Processing Methods on Phenolic Contents and Antioxidant and Anti-Proliferative Activities of Broccoli Florets
}

\author{
Hee Young Kim ${ }^{1}$, Meran Keshawa Ediriweera ${ }^{2} \mathbb{D}$, Kyung-Hwan Boo ${ }^{2} \mathbb{D}$, Chang Sook Kim $^{3}$ \\ and Somi Kim Cho 1,2,3,*iD
}

1 Interdisciplinary Graduate Program in Advanced Convergence Technology and Science, Jeju National University, Jeju 63243, Korea; hi.khyoung@gmail.com

2 Subtropical/Tropical Organism Gene Bank, Jeju National University, Jeju 63243, Korea; mk.ediriweera@gmail.com (M.K.E.); khboo@jejunu.ac.kr (K.-H.B.)

3 Department of Biotechnology, College of Applied Life Sciences, Jeju National University, Jeju 63243, Korea; cskim1225@jejunu.ac.kr

* Correspondence: somikim@jejunu.ac.kr; Tel.: +82-010-8660-1842

Citation: Kim, H.Y.; Ediriweera, M.K.; Boo, K.-H.; Kim, C.S.; Cho, S.K. Effects of Cooking and Processing Methods on Phenolic Contents and Antioxidant and Anti-Proliferative Activities of Broccoli Florets. Antioxidants 2021, 10, 641. https:// doi.org/10.3390/antiox10050641

Academic Editors: Alfredo Aires and Dimitrios Kouretas

Received: 25 March 2021

Accepted: 20 April 2021

Published: 22 April 2021

Publisher's Note: MDPI stays neutral with regard to jurisdictional claims in published maps and institutional affiliations.

Copyright: (c) 2021 by the authors. Licensee MDPI, Basel, Switzerland. This article is an open access article distributed under the terms and conditions of the Creative Commons Attribution (CC BY) license (https:/ / creativecommons.org/licenses/by/ $4.0 /)$.

\begin{abstract}
We investigated the effects of cooking (steaming and microwaving) and processing (freezedrying and hot-air-drying) methods on the antioxidant activity of broccoli florets. 2,2-diphenyl-1picrylhydrazyl $\left(\mathrm{DPPH}^{\bullet}\right), 2,2^{\prime}$-azino-bis(3-ethylbenzothiazoline-6-sulfonic acid) (ABTS ${ }^{\bullet}$ ), and alkyl ${ }^{\bullet}$ free radical scavenging assays were employed to assess anti-oxidant potentials. The cytoprotective effect against oxidative damage induced by $\mathrm{H}_{2} \mathrm{O}_{2}$ was studied using hepatocellular carcinoma (HepG2) cells. Anti-proliferative effects were assessed in MCF-7 and MDA-MB-231 breast cancer cells. L-sulforaphane in broccoli extracts was quantified using high-performance liquid chromatography (HPLC). Steam and microwave treatments caused increases in total polyphenol content (TPC), whereas the total flavonoid content (TFC) decreased following steam treatment. A slight increase in TFC was observed in the microwaved samples. Extracts of all broccoli samples showed almost identical radical scavenging and cytoprotective effects. HPLC demonstrated that steamed ( $3 \mathrm{~min}$ )freeze-dried (F-S3) and microwaved (2 min)-freeze-dried (F-M2) samples exhibited elevated levels of L-sulforaphane. In addition, the F-S3 and F-M2 extracts displayed strong anti-proliferative effects in MCF-7 cells, which correlated with L-sulforaphane content. As we observed no significant decrease in the antioxidant activity of broccoli florets, the cooking and processing methods and conditions studied here are recommended for broccoli.
\end{abstract}

Keywords: antioxidant capacity; broccoli extracts; processing; radical scavenging

\section{Introduction}

Among cruciferous vegetables, broccoli (Brassica oleracea var. italica) has been identified as a "super-food" due to its wide range of health benefits [1]. China, India, and the United States are the largest broccoli producers in the world [2]. Broccoli is a rich source of essential minerals, amino acids, dietary fiber, and various phytochemicals [3]. Glucosinolates, isothiocyanates, carotenoids, flavonoids, phenolics, xanthophylls, and sterols are the major phytochemical types found in broccoli [3]. Glucosinolates undergo enzymolysis (by myrosinase) to produce sulforaphanes, which have a wide range of biological activities including antioxidant, anti-inflammatory, and anti-cancer effects [4]. Several epidemiological studies have identified an inverse correlation between the consumption of broccoli and the risk of certain ailments including cancer, cardiovascular diseases, neurological diseases, and diabetes [5].

Although some cruciferous vegetables, including broccoli, can be eaten fresh, they are mainly consumed after cooking. Steaming and microwaving are two widely used household cooking methods [6]. Temperature can affect the levels and bioavailability 
of health-promoting bioactive components, as well as the physical characteristics and antioxidant contents of foods due to damage, release, or generation of new metabolites [6]. Steaming creates a uniform heat distribution, increasing water retention [7]. On the other hand, microwave heating results in non-uniform heat development and the rapid movement of water toward the surface, affecting the palatability of food [8].

Due to the high perishability of broccoli, its preservation through proper processing methods is crucial. Spoilage can significantly affect the amount of health-promoting bioactive components and their bioavailability, and thus must be avoided [9]. Domestic and industrial preservation methods generally include heat treatment, which can alter the levels of bioactive components and their bioavailability in Brassica vegetables, including broccoli [10]. Dehydration is the main principle of many food processing methods. The main aim of dehydration is to minimize microbial spoilage and the rate of deterioration by lowering the water content of food [11]. The water content of food has been reported to affect multiple spoilage pathways through direct roles as a reactant or product [11]. Freezedrying is one of the most successful food preservation techniques for perishable food items. During freeze-drying, water is removed from food material through the sublimation of ice [12]. Freeze-drying has been reported to maintain the appearance, shape, flavor, and biological activities of food items, making it a promising drying technique [12].

The present investigation explored the effects of various cooking (steaming and microwaving) and processing (air drying and freeze-drying) methods on the antioxidant activity, effects on breast cancer cell proliferation, and hydrogen peroxide $\left(\mathrm{H}_{2} \mathrm{O}_{2}\right)$-induced reactive oxygen species (ROS) production of broccoli florets.

\section{Materials and Methods}

\subsection{Plant Materials}

Fresh broccoli (Brassica oleracea var. italica) was purchased from local markets on Jeju Island, South Korea in 2020. Broccoli florets were manually removed using a clean sharp knife, washed with tap water, and dried on paper towels.

\subsection{Cooking Processes}

After drying on paper towels, broccoli florets were mixed well, and then $5200 \mathrm{~g}$ samples were taken and divided into four portions (1300 g per portion). One portion $(1300 \mathrm{~g})$ was kept raw and others were cooked using two different methods in triplicate, as described below.

\subsubsection{Steaming}

A sample of $1300 \mathrm{~g}$ of broccoli florets was steamed using a steam vessel with $200 \mathrm{~mL}$ of water for $3 \mathrm{~min}$.

\subsubsection{Microwave Cooking}

A sample of $1300 \mathrm{~g}$ of broccoli florets was placed in a glass dish with $100 \mathrm{~mL}$ of water. The dishes were covered with cooking bags with holes and cooked in a commercial microwave oven for $2 \mathrm{~min}$ at $100-120^{\circ} \mathrm{C}(230 \mathrm{~V}-50 \mathrm{~Hz}$ AC, $700 \mathrm{~W})$. Another sample of $1300 \mathrm{~g}$ of broccoli florets was cooked in the same microwave oven for $4 \mathrm{~min}$ under the same conditions.

\subsection{Drying Experiments}

Steamed, microwaved (for 2 and $4 \mathrm{~min}$ ), and fresh broccoli florets were subjected to both vacuum freeze-drying and hot-air-drying processes, as described below.

\subsubsection{Vacuum Freeze-Drying}

Steamed, microwaved, and raw broccoli florets $(650 \mathrm{~g})$ were vacuum freeze-dried (LP 20; Ilshinbiobase, Dongducheon, Korea) for 2 days and stored in airtight plastic bags. 


\subsubsection{Hot-Air-Drying}

Broccoli florets were spread evenly on a tray, placed in the drying chamber of a hot-air dryer, and dried at $55{ }^{\circ} \mathrm{C}$ for $48 \mathrm{~h}$. The cooking and drying procedures employed in the present study are shown as a flow chart in Figure 1.

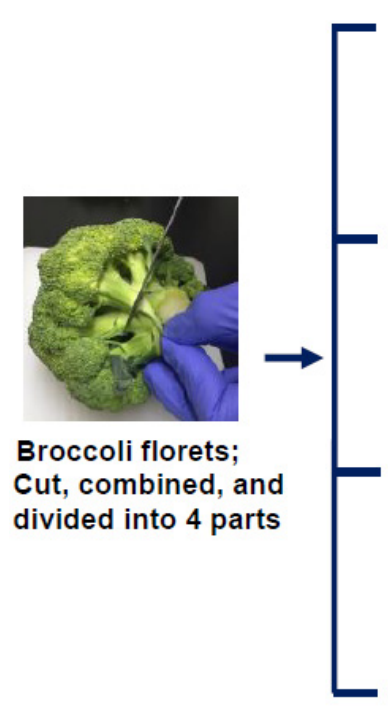

-

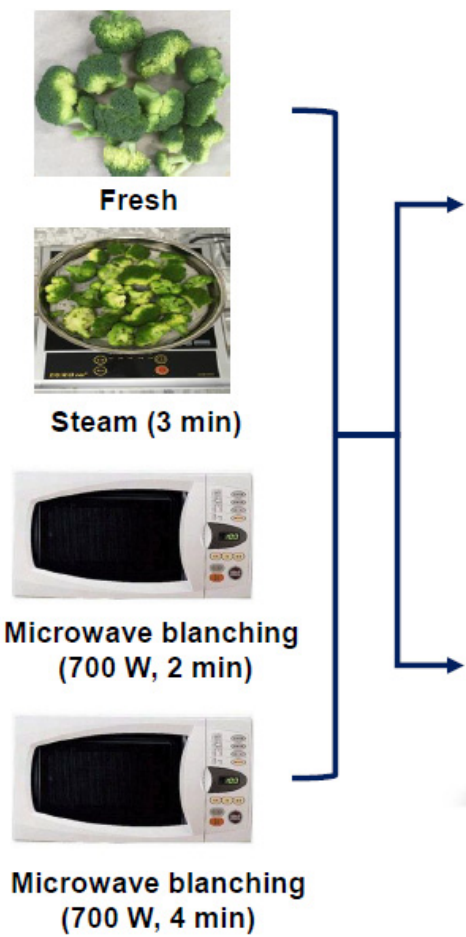

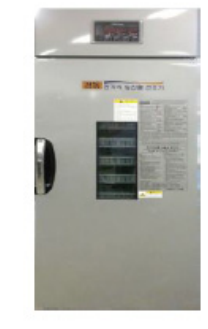

Hot air drying $\left(55^{\circ} \mathrm{C}, 48 \mathrm{~h}\right)$

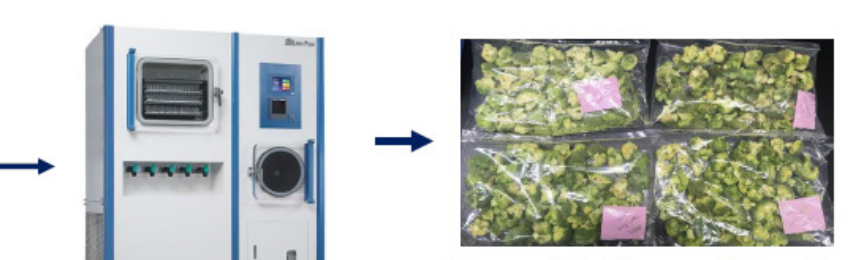

Freeze dried broccoli florets

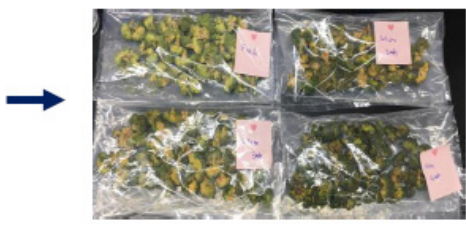

Hot air dried broccoli florets
Freeze drying

$(48 \mathrm{~h})$

(700 W, $4 \mathrm{~min}$ )

Figure 1. Flow diagram of the cooking and processing methods used for broccoli in the present study.

\subsection{Extraction of Plant Material}

Following vacuum freeze-drying and hot-air-drying, $10 \mathrm{~g}$ of each powdered broccoli sample was extracted into $500 \mathrm{~mL}$ of $80 \%$ methanol (three times) with sonication for $45 \mathrm{~min}$ at room temperature. The resulting extracts were evaporated using a rotary evaporator and stored at $-20^{\circ} \mathrm{C}$ until used. The extracts were named and coded as follows: freshhot-air-dried (H-F), steamed (3 min)-hot-air-dried (H-S3), microwaved (2 min)-hot-airdried (H-M2), microwaved (4 min)-hot-air-dried (H-M4), fresh-freeze-dried (F-F), steamed (3 min)-freeze-dried (F-S3), microwaved (2 min)-freeze-dried (F-M2), and microwaved (4 min)-freeze-dried (F-M4).

\subsection{Determination of Total Polyphenol (TPC) and Flavonoid (TFC) Contents}

The total polyphenol content (TPC) was determined as previously described [13]. Briefly, $1.375 \mathrm{~mL}$ of water and $125 \mu \mathrm{L}$ of an individual extract were mixed with $500 \mu \mathrm{L}$ of Folin-Ciocalteu phenol reagent and incubated for $5 \mathrm{~min}$. After $5 \mathrm{~min}$ of incubation, $1 \mathrm{~mL}$ of $10 \% \mathrm{Na}_{2} \mathrm{CO}_{3}$ was added to the reaction mixture, which was incubated at room temperature for a further $30 \mathrm{~min}$ in the dark. Following incubation, the absorbance was recorded using a microplate reader. TPC was expressed as milligrams of gallic acid equivalent (GAE) per gram of extract. To assess the TFC contents of the extracts, we followed a previouslydescribed method [13]. Briefly, $40 \mu \mathrm{L}$ of an extract was mixed with $80 \mu \mathrm{L}$ of distilled water and $6 \mu \mathrm{L}$ of $5 \% \mathrm{NaNO}_{2}$. After 5 min of incubation, $12 \mu \mathrm{L}$ of $10 \% \mathrm{AlCl}_{3}$ was mixed with the reaction mixture, which was incubated at room temperature for $6 \mathrm{~min}$. Following incubation, $40 \mu \mathrm{L}$ of $1 \mathrm{~N} \mathrm{NaOH}$ was added to the reaction mixture and its absorbance was measured at $510 \mathrm{~nm}$ using a microplate reader. TFC was expressed as milligrams of rutin equivalent (RE) per gram of extract. 


\subsection{Analysis of Antioxidant Activity}

2.6.1. 2,2-Diphenyl-1-picrylhydrazyl (DPPH) Radical Scavenging Activity Based on Electron Spin Resonance (ESR)

The DPPH radical scavenging activity of the samples was estimated using ESR as previously described with slight modifications [14]. Reaction mixtures were prepared by mixing $30 \mu \mathrm{L}$ of an extract with $30 \mu \mathrm{L}$ of freshly prepared DPPH solution $(60 \mu \mathrm{M}$ in ethanol solution). Following mixing, they were incubated at room temperature for 2 min and transferred to Teflon ${ }^{\mathrm{TM}}$ capillary tubes using a syringe. ESR spectra were recorded using the following parameters: frequency, $9.43 \mathrm{GHz}$; power, $5 \mathrm{~mW}$; sweep width, $10 \mathrm{mT}$; sweep time, $30 \mathrm{~s}$; time constant, $0.03 \mathrm{~s}$; amplitude, 500; and modulation width, $0.8 \mathrm{mT}$. A magnetic ESR standard $\left(\mathrm{Mn}^{2+}\right.$ marker) was used for comparison of signal intensities, and results were expressed as relative height ratios. Catechin was used as the positive control in this experiment. The percentage radical scavenging activity of each extract was calculated using the following formula: (Absorbance of the control groupabsorbance treated group) $\div$ Absorbance control group) $\times 100 \%$. Following percentage radical scavenging activity calculations, $\mathrm{EC}_{50}$ values for each extract were generated using GraphPad Prism 7.0 software.

\subsubsection{Alkyl Radical Scavenging Activity Based on ESR}

Prior to analysis, reaction mixtures were prepared by mixing $20 \mu \mathrm{L}$ of distilled water, $20 \mu \mathrm{L}$ of extract, $20 \mu \mathrm{L}$ of $40 \mathrm{mM}$ (-(4-pyridyl-1-oxide)-N-tert -butylnitrone (4-POBN), and $20 \mu \mathrm{L}$ of $40 \mathrm{mM}$ 2,2'-Azobis(2-amidinopropane) dihydrochloride (AAPH). Then, the reaction mixtures were incubated at $37^{\circ} \mathrm{C}$ for $30 \mathrm{~min}$ and transferred to Teflon ${ }^{\mathrm{TM}}$ capillary tubes using a syringe. A JES-FA200 ESR spectrometer (JEOL, Tokyo, Japan) was utilized to measure alkyl radical scavenging activity at the Bio-Health Materials Core-Facility in Jeju National University. The following parameter settings were used to record ESR spectra: frequency, $9.43 \mathrm{GHz}$; power, $7 \mathrm{~mW}$; sweep width, $10 \mathrm{mT}$; sweep time, $30 \mathrm{~s}$; time constant, $0.03 \mathrm{~s}$; amplitude, 500; and modulation width, $0.2 \mathrm{mT}$. A magnetic ESR standard $\left(\mathrm{Mn}^{2+}\right.$ marker) was used for comparison of signal intensities and results were expressed as relative height ratios. Catechin was used as the positive control in this experiment. The percentage radical scavenging activity of each extract was calculated using the following formula: (Absorbance of the control group - absorbance treated group) $\div$ Absorbance control group) $\times 100 \%$. Following percentage radical scavenging activity calculations, $\mathrm{EC}_{50}$ values for each extract were generated using GraphPad Prism 7.0 software.

2.6.3. 2,2'-Azino-bis(3-ethylbenzothiazoline-6-sulfonic Acid) (ABTS) Radical Scavenging Activity Assay

The ABTS radical scavenging activity assay was performed as previously described with slight modifications [14]. Prior to the assay, fresh ABTS radical solution $(7 \mathrm{mM}$ ABTS in $2.45 \mathrm{mM}$ potassium persulfate) was prepared and incubated for $20 \mathrm{~h}$ at room temperature. Prepared ABTS stock solution was then diluted with distilled water to obtain an absorbance of $0.700 \pm 0.005$ at $734 \mathrm{~nm}$. Then, $100 \mu \mathrm{L}$ of each broccoli extract was mixed with $900 \mu \mathrm{L}$ of ABTS solution (diluted) and incubated for $2 \mathrm{~min}$. The ABTS radical scavenging activity was measured using the recorded absorbance values, with $\alpha$-tocopherol as the positive control. The percentage radical scavenging activity of each extract was calculated using the following formula: (Absorbance of the control groupabsorbance treated group) $\div$ Absorbance control group) $\times 100 \%$. Following percentage radical scavenging activity calculations, $\mathrm{EC}_{50}$ values for each extract were generated using GraphPad Prism 7.0 software.

\subsection{Cell Culture}

Human triple-negative breast cancer (MDA-MB-231), estrogen receptor-positive (MCF7), and normal mammary epithelial cells (MCF-10A) were cultured using the cell culture media recommended by the American Type Culture Collection (ATCC) and maintained 
at $37^{\circ} \mathrm{C}$ in an atmosphere of $5 \% \mathrm{CO}_{2}$. The hepatocellular carcinoma (HepG2) cell line obtained from KCLB (Korean Cell line Bank) was cultured in RPMI1640 (Roswell Park Memorial Institute Medium) and maintained at $37^{\circ} \mathrm{C}$ in an atmosphere of $5 \% \mathrm{CO}_{2}$.

\subsection{3-(4,5-Dimethylthiazol-2-yl)-2,5-diphenyltetrazolium Bromide (MTT) Assay}

The MTT assay was conducted as previously described [15]. Briefly, MDA-MB-231, MCF-7 and MCF-10A cells (5000 cells/well) were seeded in 96-well plates and incubated for $24 \mathrm{~h}$. Then, the cells were exposed to various extracts for $48 \mathrm{~h}$. Following $48 \mathrm{~h}$ of incubation, the cells were washed with phosphate-buffered saline (PBS) and incubated with MTT solution $(20 \mu \mathrm{L}$ at $1 \mathrm{mg} / \mathrm{mL})$ for $4 \mathrm{~h}$ at $37^{\circ} \mathrm{C}$. Then, $200 \mu \mathrm{L}$ of dimethyl sulfoxide (DMSO) was added to each well, and the plates were shaken for 45 min on a plate shaker. The absorbance of each well was measured at $570 \mathrm{~nm}$ using a microplate reader, and the percentage of cell viability was calculated as described in our recent study. The percentage of cell viability was calculated using the formula (Absorbance of the control group absorbance treated group) $\div$ Absorbance control group) $\times 100 \%$. The percentage of cell viability values was then used to calculate $\mathrm{IC}_{50}$ for each extract using GraphPad Prism 7.0 software (La Jolla, CA, USA).

\subsection{Measurement of Intracellular ROS Generation}

The probe $2^{\prime}, 7^{\prime}$-dichlorodihydrofluorescein diacetate $\left(\mathrm{H}_{2} \mathrm{DCFDA}\right)$ was used to measure intracellular ROS production. Briefly, HepG2 cells (40,000 cells/well) were cultured in 96-well plates and incubated for $24 \mathrm{~h}$, pre-treated with broccoli extracts for $6 \mathrm{~h}$, and then exposed to $\mathrm{H}_{2} \mathrm{O}_{2}$ (final concentration, $300 \mu \mathrm{M}$ ) for $10 \mathrm{~min}$ to induce ROS formation. Cells were then incubated with $\mathrm{H}_{2}$ DCFDA for $10 \mathrm{~min}$. Following incubation, fluorescence intensity was measured using a microplate reader at excitation and emission wavelengths of 525 and $475 \mathrm{~nm}$, respectively.

\subsection{Quantification of L-Sulforaphane via High-Performance Liquid Chromatography (HPLC)}

Prior to quantification using HPLC, each broccoli sample (F-F, F-S3, F-M2, F-M4, H-F, H-S3, H-M2, and H-M4) was subjected to small-scale extraction using distilled water and dichloromethane. Briefly, $1 \mathrm{~g}$ of each broccoli sample was mixed with $4 \mathrm{~mL}$ of distilled water and vortexed for $10 \mathrm{~min}$ at room temperature. After resting for $10 \mathrm{~min}, 15 \mathrm{~mL}$ of dichloromethane was added, and the mixture was vortexed for $15 \mathrm{~min}$. The resulting extracts were filtered, evaporated, and subjected to HPLC analysis. The HPLC system was equipped with an ultraviolet detector (HPLC-UVD) (Shimadzu CBM-20A, Tokyo, Japan) comprising a CBM-20A system controller, SIL-20A autosampler, SPD-M20A diode array detector, LC-20AD solvent delivery unit, DGU-20A3R degassing unit, and CTO-20A column oven. The extracts $(20 \mu \mathrm{L})$ were separated on a Shim-pack ODS $5-\mu m$ column (Shimadzu, Kyoto, Japan) at $40{ }^{\circ} \mathrm{C}$ with a gradient solvent system consisting of wateracetonitrile $(80: 20$ to $0: 100 \mathrm{v} / \mathrm{v})$ for $50 \mathrm{~min}$. The flow rate was $1.0 \mathrm{~mL} / \mathrm{min}$, and the detection wavelength was $205 \mathrm{~nm}$. The L-sulforaphane levels in each sample were quantified using a standard curve and expressed as $\mu \mathrm{g} / \mathrm{g}$ of dry weight.

\subsection{Statistical Analysis}

All experiments were performed in triplicate. GraphPad Prism 7.0 software (La Jolla, CA, USA) was used for statistical analysis. Statistical analysis of TPC, TFC, and intracellular ROS generation was performed using one-way analysis of variance (ANOVA) with Tukey's multiple comparison test (at 95\% level of significance). Data were expressed as the mean \pm standard deviation (SD), and statistical significance was identified at $p<0.05$.

\section{Results and Discussion}

3.1. Total Polyphenol Content (TPC) and Total Flavonoid Content (TFC) of Broccoli Floret Extracts

Phenolics and flavonoids are large groups of plant secondary metabolites that are abundant in fruits and vegetables [16,17]. Phenolics and flavonoids are structurally and 
functionally diverse and have a wide range of biological activities, making them attractive ingredients for food technology research [18]. Notably, phenolics and flavonoids have gained the attention of many researchers in the field of food technology as potent antioxidants [18]. In broccoli, phenolics and flavonoids, including gallic acid, ellagic acid, salicylic acid, syringic acid, caffeic acid, ferulic acid, sinapic acid, isoquercetin, hyperoside, and rutin are found in differing quantities [19].

The TPCs of extracts from broccoli florets subjected to various cooking and processing conditions are shown in Figure 2A. First, we compared the TPC between fresh hot-air-dried (H-F) and fresh freeze-dried (F-F) samples. The extracts of F-F and H-F showed nearly equal TPC (Figure 2A). After comparing the TPCs of F-F and H-F, we compared the TPCs of H-S3, $\mathrm{H}-\mathrm{M} 2$, and H-M4 with H-F to determine whether significant differences existed among the hot-air-dried groups: H-F vs. H-S3, H-F vs. H-M2, and H-F vs. H-M4. According to the TPC of extracts from hot-air-dried samples, H-S3, H-M2, and H-M4 contained higher TPC than the H-F sample, and this difference was significant (Figure 2A). TPCs of the extracts of H-F, H-S3, H-M2, and H-M4 were $1.36 \pm 0.07,1.75 \pm 0.07,1.82 \pm 0.14$, and $1.85 \pm 0.15 \mathrm{mg} \mathrm{GAE} / \mathrm{g}$, respectively. Consistent with our findings, Turkmen et al. (2005) reported that heat treatment increased the TPC of broccoli by increasing the levels of free phenolics through disruption of inter-molecular interactions between phenolics [20]. Gliszczyńska-Świgło et al. (2006) demonstrated similar effects from steaming on the TPC of broccoli [21]. Şengül et al. (2014) showed that steaming can increase TPC in broccoli [22].

Then, the TPCs of the extracts of freeze-dried samples (F-S3, F-M2, and F-M4) were compared with the TPC of the F-F sample. F-S3 and F-M2 contained higher TPC than the F-F sample. The TPCs of freeze-dried samples F-F, F-S3, F-M2, and F-M4 were $1.36 \pm 0.09$, $1.46 \pm 0.06,1.53 \pm 0.13$, and $1.29 \pm 0.03 \mathrm{mg} \mathrm{GAE} / \mathrm{g}$, respectively. Among these, the group comparison of F-F vs. F-M2 showed a significant increase in TPC (Figure 2A). A recent investigation reported elevated TPC in broccoli following microwave treatment [23]. The group comparison F-F vs. F-S3 also showed an increase in TPC, but this difference was not significant. TPC in the group F-F vs. F-M4 comparison showed a significant decrease (Figure 2A). In contrast, in the investigation by Şengül et al. (2014) [22], broccoli florets subjected to microwaving showed reduced TPC relative to raw samples, indicating that microwave can cause physical and chemical alterations to vegetables.

In addition, the TPCs of steamed hot-air-dried, steamed freeze-dried, microwaved hot-air-dried, and microwaved freeze-dried samples were grouped (H-S3 vs. F-S3, H-M2 vs. F-M2, H-M4 vs. F-M4, H-S3 vs. H-M2, H-S3 vs. H-M4, F-S3 vs. F-M2, and F-S3 vs. F-M4) and compared to determine whether hot-air-drying or freeze-drying had a significant effect on the TPC of cooked samples. Among these comparisons, the TPCs of H-S3 vs. F-S3, $\mathrm{H}-\mathrm{M} 2$ vs. F-M2, and H-M4 vs. F-M4 showed an interesting pattern wherein freeze-dried samples (F-S3, F-M2, and F-M4) exhibited reduced TPC compared to hot-air-dried (H-S3, $\mathrm{H}-\mathrm{M} 2$, and H-M4) samples (Figure 2A). Although the groups containing steamed hot-airdried and microwaved hot-air-dried samples (H-S3 vs. H-M2 and H-S3 vs. H-M4) did not show a statistically significant difference in TPC, microwaved-hot-air-dried samples (H-M2 and H-M4) showed increased TPC compared with steamed-hot-air-dried samples (H-S3; Figure 2A). Similar to the H-S3 vs. H-M2 and H-S3 vs. H-M4 comparisons, TPCs of the steamed freeze-dried and microwaved freeze-dried groups (F-S3 vs. F-M2 and F-S3 vs. F-M4) showed no statistically significant difference (Figure 2A). However, F-M2 had a slightly higher TPC than F-S3, while F-M4 showed a slightly reduced TPC compared with F-S3 (Figure 2A). 

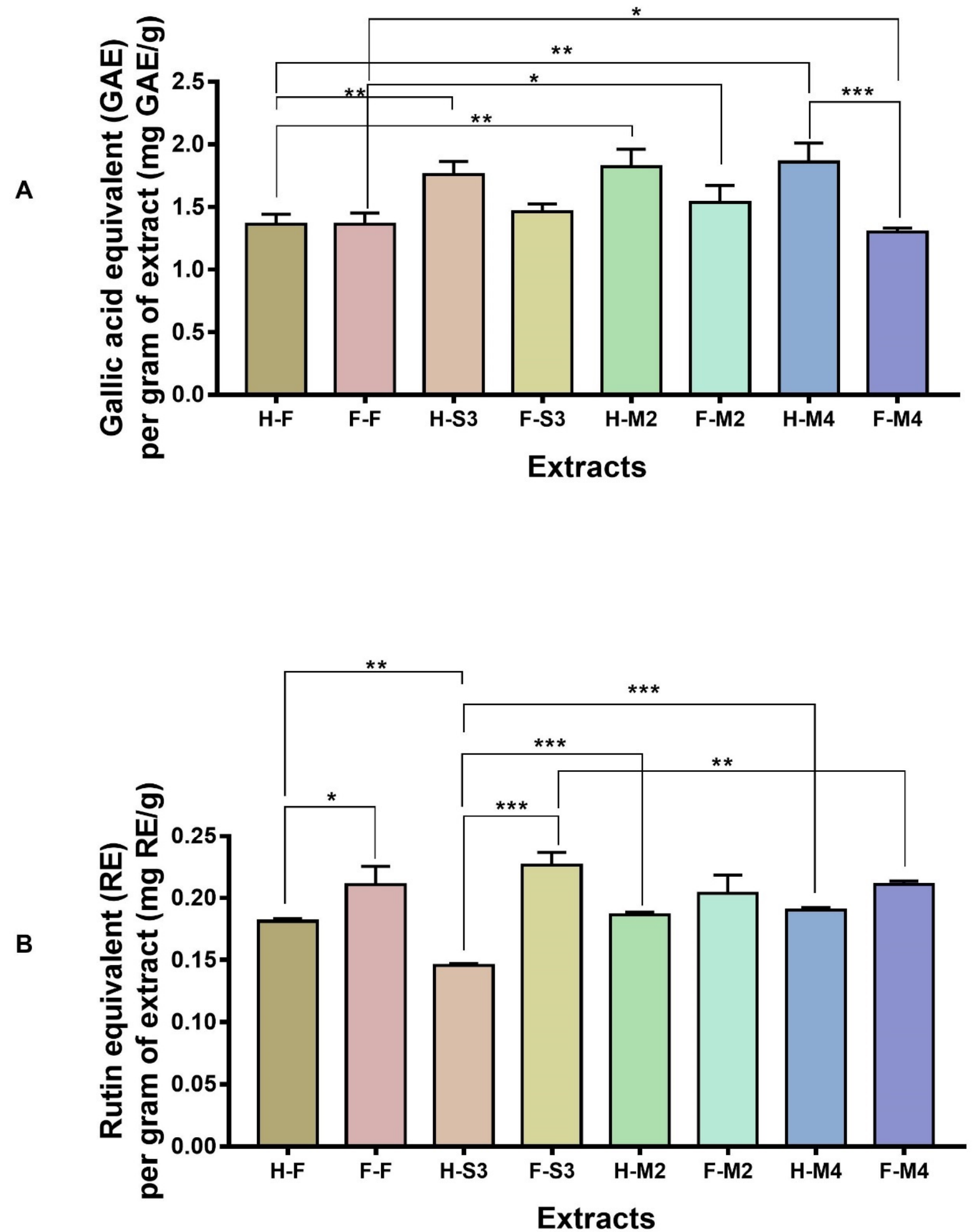

Figure 2. TPC (A) and TFC (B) of fresh-hot-air-dried (H-F), steamed (3 min)-hot-air-dried (H-S3), microwaved (2 min)-hotair-dried (H-M2), microwaved (4 min)-hot-air-dried (H-M4), fresh-freeze-dried (F-F), steamed (3 min)-freeze-dried (F-S3), microwaved (2 min)-freeze-dried (F-M2), and microwaved (4 min)-freeze-dried (F-M4) samples. Statistical comparison among groups was carried out using one-way ANOVA with Tukey's multiple comparison test. ${ }^{*} p<0.05,{ }^{* *} p<0.01$, and $* * * p<0.001$. 
In contrast to the TPC data, the TFCs of extracts of F-F and H-F samples showed differing patterns (Figure 2B). TFCs of H-F and F-F samples were first compared. The extract of F-F $(0.21 \pm 0.01 \mathrm{mg} \mathrm{RE} / \mathrm{g})$ had a significantly higher TFC than $\mathrm{H}-\mathrm{F}(0.18 \pm 0.001 \mathrm{mg} \mathrm{RE} / \mathrm{g})$ (Figure 2B). Then, we compared the TFCs of H-S3, H-M2, and H-M4 with the TFC of H-F according to the following groups: H-F vs. H-S3, H-F vs. H-M2, and H-F vs. H-M4. The group comparison of H-Fand H-S3 showed a significant relationship, with $\mathrm{H}-\mathrm{S} 3$ having a lower TFC than the H-F sample (Figure 2B). Recently, Wu et al. (2019) reported that steam treatment can decrease the concentration of many kaempferol- and quercetin-derived flavonoids in broccoli [24]. H-M2 and H-M4 displayed slightly higher TFCs than H-F, with a non-significant relationship (Figure 2B). Similar to our results, Wu et al. (2019) also detected slight increases in flavonoid concentrations following microwave treatment [24]. The TFCs of the extracts from H-S3, H-M2, and H-M4 were $0.14 \pm 0.001,0.18 \pm 0.002$, and $0.19 \pm 0.002 \mathrm{mg} \mathrm{RE} / \mathrm{g}$, respectively.

The total flavonoids of extracts of freeze-dried samples (F-S3, F-M2, and F-M4) were then compared with the total flavonoids of F-F sample. Freeze-dried samples exhibited total flavonoid content nearly equal to the total flavonoid content of the F-F sample (Figure 2B). The TFCs of freeze-dried samples F-S3, F-M2, and F-M4 were $0.22 \pm 0.01,0.2 \pm 0.01$, and $0.21 \pm 0.002 \mathrm{mg} \mathrm{RE} / \mathrm{g}$, respectively. No significant difference in TFC was observed among the groups (Figure 2B). The TFCs of steamed hot-air-dried, steamed freeze-dried, microwaved hot-air-dried, and microwaved freeze-dried samples were grouped (H-S3 vs. F-S3, H-M2 vs. F-M2, H-M4 vs. F-M4, H-S3 vs. H-M2, H-S3 vs. H-M4, F-S3 vs. F-M2, and F-S3 vs. F-M4) and compared to determine whether hot-air-drying or freeze-drying had significant effects on the TFC of cooked samples. Among these comparisons, the TFCs of the groups H-S3 vs. F-S3, H-M2 vs. F-M2, and H-M4 vs. F-M4 displayed the opposite patterns to TPC, with freeze-dried samples (F-S3, F-M2, and F-M4) having higher TFC than hot-air-dried (H-S3, H-M2, and H-M4) samples (Figure 2B). The comparisons of H-S3 vs. H-M2 and H-S3 vs. H-M4, between steamed-hot-air-dried and microwaved-hotair-dried samples, showed statistically significant differences in TFC, with microwaved hot-air-dried samples (H-M2 and H-M4) having elevated TFCs compared to the steamed hot-air-dried sample H-S3 (Figure 2B). Compared to F-S3, F-M2 and F-M4 showed reduced TFC (Figure 2B) and the TFC comparison of F-S3 vs. F-M4 showed a statistically significant difference (Figure 2B).

\subsection{Antioxidant Activities}

Several studies have investigated the effects of different cooking methods on the antioxidant activity of broccoli [20-24]. To obtain a comprehensive profile of the antioxidant activities of various broccoli extracts, we employed three antioxidant assessment methods, namely $\mathrm{ABTS}^{\bullet}, \mathrm{ESR}^{-\mathrm{DPPH}}{ }^{\bullet}$, and ESR-alkyl ${ }^{\bullet}$. These assays have been widely used to assess the free radical scavenging activities of various vegetables, fruits, individual compounds, and biological systems [14]. ABTS ${ }^{\bullet}$ is a colored molecule that can be reduced to colorless ABTS when mixed with any oxidizable agent [25]. Compared to colorimetric methods, ESR spectrometry is a sensitive technique used to assess free radicals or transition metal ions [26]. As shown in Figure 3A-C, the ABTS ${ }^{\bullet}, \mathrm{ESR}^{-D P P H}{ }^{\bullet}$, and ESR-alkyl ${ }^{\bullet}$ scavenging activities of broccoli extracts (F-F, F-S3, F-M2, F-M4, H-F, H-S3, H-M2, and H-M4) increased with increasing concentration. All broccoli extracts displayed greater than $70 \% \mathrm{ABTS}^{\bullet}$ and ESR-DPPH ${ }^{\bullet}$ radical scavenging activities at the highest doses tested $(10$ and $1 \mathrm{mg} / \mathrm{mL}$, respectively) (Figure 3A,B). Similar to the results for ABTS $\bullet$ and ESR-DPPH ${ }^{\bullet}$ radical scavenging activities, all broccoli extracts also demonstrated ESR-alkyl ${ }^{\bullet}$ scavenging activities in a dose-dependent manner, with more than $50 \%$ inhibition observed at the highest extract doses (Figure $3 \mathrm{C}$ ). The $\mathrm{EC}_{50}$ values obtained from each antioxidant assay are listed in Table 1. From these $\mathrm{EC}_{50}$ values, it is apparent that the H-M4 extract had strong radical scavenging effects. As shown in Figure 2A, a significant increase in TPC, one of the major contributors to antioxidant activity, may contribute to the enhanced antioxidant activity of H-M4. All other extracts displayed similar 


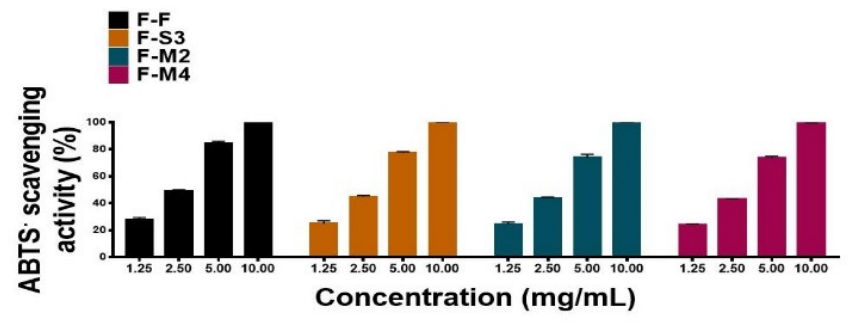

A
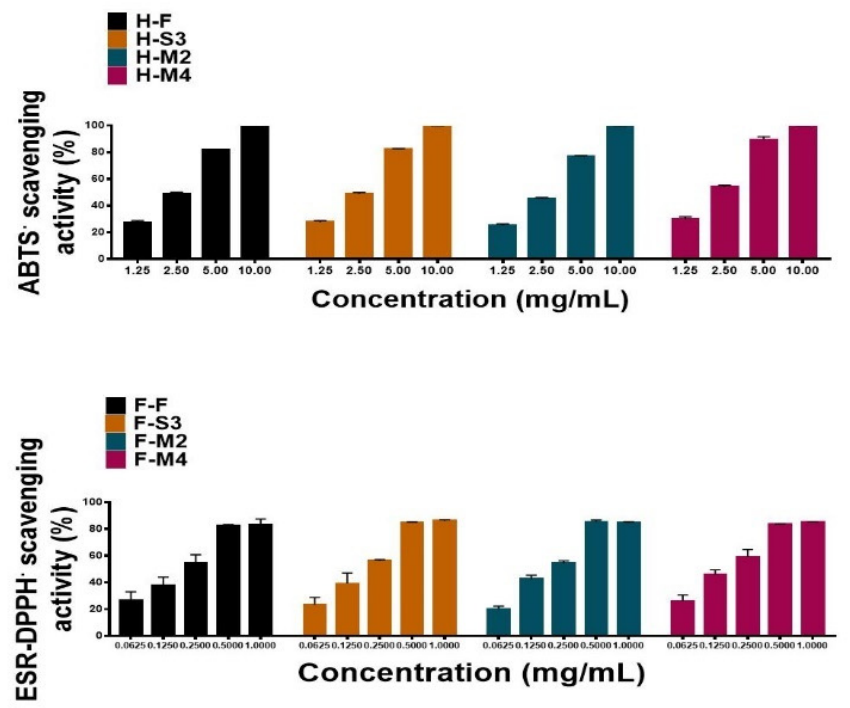

B
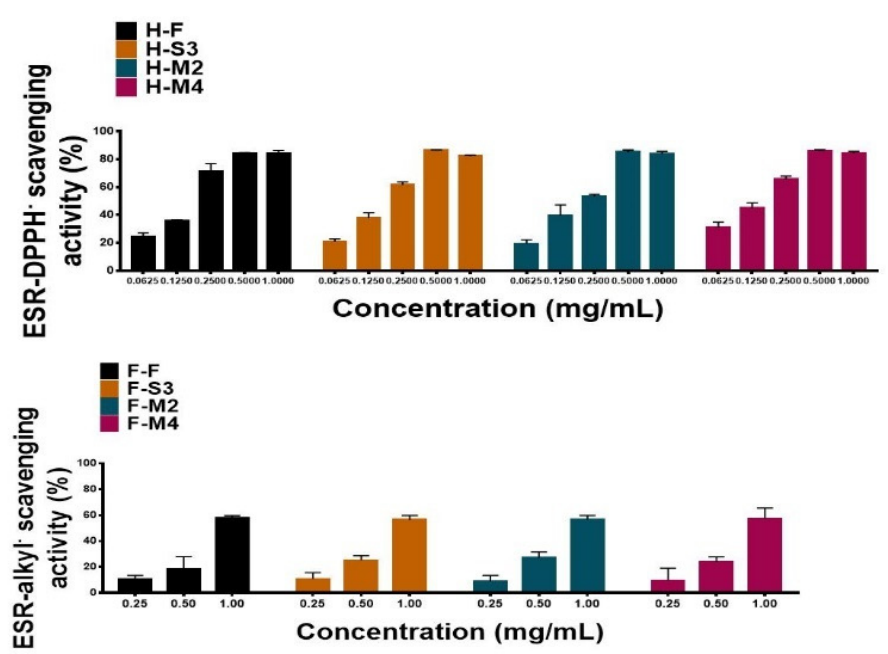

C

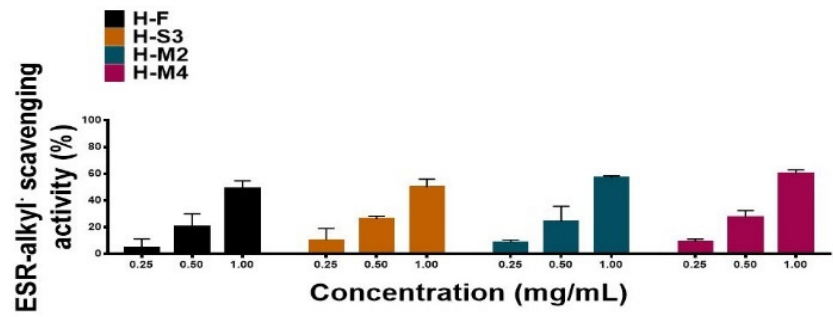

Figure 3. $\mathrm{ABTS}^{\bullet}(\mathbf{A}), \mathrm{DPPH}^{\bullet}(\mathbf{B})$, and alkyl ${ }^{\bullet}(\mathrm{C})$ free radical scavenging potentials of broccoli extracts [fresh-hot-air-dried (H-F), steamed (3 min)-hot-air-dried (H-S3), microwaved (2 min)-hot-air-dried (HM2), microwaved (4 min)-hot-air-dried (H-M4), fresh-freeze-dried (F-F), steamed (3 min)-freeze-dried (F-S3), microwaved (2 min)-freeze-dried (F-M2), and microwaved (4 min)-freeze-dried (F-M4)]. 
Table 1. $\mathrm{EC}_{50}(\mathrm{mg} / \mathrm{mL})$ values obtained from various antioxidant assays for broccoli extracts (H-F, H-S3, H-M2, H-M4, F-F, F-S3, F-M2, and F-M4).

\begin{tabular}{cccc}
\hline & ABTS & ESR-DPPH $^{\bullet}$ & ESR-alkyl $^{\bullet}$ \\
\hline H-F & 1.98 & 0.15 & 1.49 \\
H-S3 & 1.97 & 0.17 & 1.26 \\
H-M2 & 2.23 & 0.18 & 1.17 \\
H-M4 & 1.67 & 0.13 & 1.03 \\
F-F & 1.92 & 0.17 & 1.22 \\
F-S3 & 2.23 & 0.16 & 1.12 \\
F-M2 & 2.35 & 0.17 & 1.11 \\
F-M4 & 2.39 & 0.15 & 1.18 \\
\hline
\end{tabular}

$\mathrm{EC}_{50}$ values (Table 1), suggesting that the tested cooking and processing techniques did not significantly alter the antioxidant activities of broccoli florets. The $\mathrm{EC}_{50}$ values obtained for positive controls catechin in ESR-DPPH ${ }^{\bullet}$ and ESR-alkyl ${ }^{\bullet}$ and $\alpha$-tocopherol in ABTS $^{\bullet}$ assays were $2.83 \mu \mathrm{M}, 11.85 \mu \mathrm{M}$ and $19.53 \mu \mathrm{M}$, respectively. Although all broccoli extracts showed antioxidant potentials in the $\mathrm{ABTS}^{\bullet}, \mathrm{ESR}^{\mathrm{DPPH}}{ }^{\bullet}$, and ESR-alkyl ${ }^{\bullet}$ assays, these activities did not correlate with the TPC and TFC values. The reason for the highly similar antioxidant potentials (based on $\mathrm{EC}_{50}$ values) (Table 1) among broccoli extracts may be related to the presence of differing quantities of secondary metabolites other than phenolics and flavonoids, which exert stronger antioxidant potentials that mask the effects of phenolics and flavonoids. Therefore, identification and quantification of other secondary metabolites are warranted to obtain a comprehensive picture of the antioxidant potentials and associated secondary metabolites in broccoli extracts. Glucosinolates and isothiocyanates have been reported to contribute strongly to the antioxidant potential of broccoli extracts [4].

\section{3. $\mathrm{H}_{2} \mathrm{O}_{2}$-Induced ROS Production}

Oxidative stress, an imbalance in the production and elimination of ROS, has been reported to play key roles in the pathogenesis of various liver disorders, including liver cancer [27]. $\mathrm{H}_{2} \mathrm{O}_{2}$ is one of the key causes of oxidative injury, as it can be easily transformed into hydroxyl radicals, which are considered destructive free radicals [14]. $\mathrm{H}_{2} \mathrm{O}_{2}$ has been used as an inducer of ROS-mediated oxidative stress in several in vitro models [14]. Moreover, a number of plant extracts and natural compounds have been reported to reduce $\mathrm{H}_{2} \mathrm{O}_{2}$-induced ROS production based on in vitro studies [14]. Here, we examined the effects of broccoli extracts on ROS generation in HepG2 cells exposed to $\mathrm{H}_{2} \mathrm{O}_{2}(300 \mu \mathrm{M})$. As indicated in Figure 4, $\mathrm{H}_{2} \mathrm{O}_{2}$ treatment significantly increased $\mathrm{ROS}$ production, with an almost two-fold increase relative to the untreated controls. However, intracellular ROS generation was significantly decreased in the experimental groups pre-treated with broccoli extracts compared to the $\mathrm{H}_{2} \mathrm{O}_{2}$-induced groups (Figure 4). Among these experimental groups, H-S3, H-M4, F-S3, and F-M4 showed greater reductions in intracellular ROS generation than other groups (Figure 4). These observations suggest that $\mathrm{H}_{2} \mathrm{O}_{2}$ can induce ROS generation in HepG2 cells and the extracts of cooked broccoli can effectively reduce $\mathrm{H}_{2} \mathrm{O}_{2}$-induced ROS production (Figure 4). Studies assessing the effects of broccoli extracts on $\mathrm{H}_{2} \mathrm{O}_{2}$-induced ROS production are extremely limited. Park et al. (2014) reported cytoprotective effects of broccoli extracts in PC12 cells following exposure to $\mathrm{H}_{2} \mathrm{O}_{2}$ [28]. Moreover, a recent study demonstrated that sulforaphane, which is found in broccoli, could effectively attenuate $\mathrm{H}_{2} \mathrm{O}_{2}$-induced oxidative stress in human osteoarthritic chondrocytes [29]. Another recent study reported that sulforaphane can attenuate $\mathrm{H}_{2} \mathrm{O}_{2}$-induced oxidative stress in vitro [30]. 

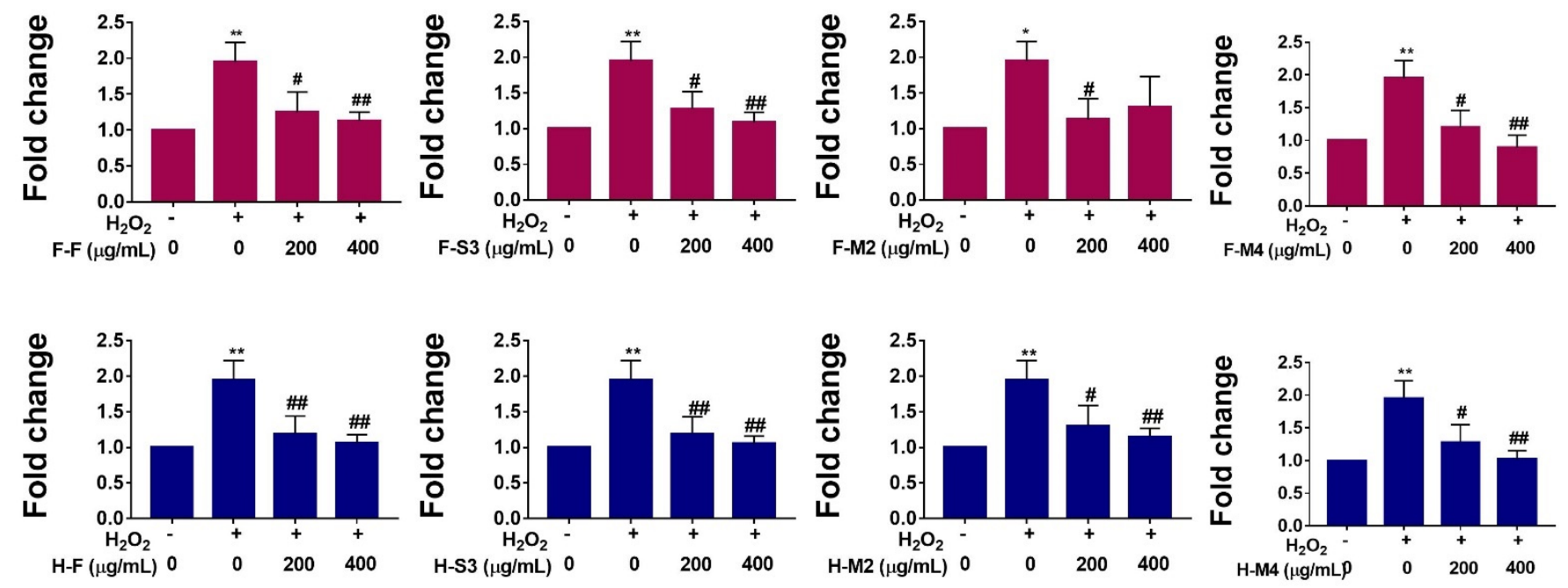

Figure 4. Broccoli extracts (fresh-hot-air-dried (H-F), steamed (3 min)-hot-air-dried (H-S3), microwaved (2 min)-hot-airdried (H-M2), microwaved (4 min)-hot-air-dried (H-M4), fresh-freeze-dried (F-F), steamed (3 min)-freeze-dried (F-S3), microwaved (2 min)-freeze-dried (F-M2), and microwaved (4 min)-freeze-dried (F-M4)) inhibit $\mathrm{H}_{2} \mathrm{O}_{2}$-induced reactive oxygen species (ROS) production. HepG2 cells were pretreated with 200 or $400 \mu \mathrm{g} / \mathrm{mL}$ broccoli extracts prior to exposure to $300 \mathrm{\mu M} \mathrm{H}_{2} \mathrm{O}_{2}$ for $10 \mathrm{~min} .2^{\prime}$, 7-dichlorodihydrofluorescein ( $\mathrm{H}_{2} \mathrm{DCFDA}$ ) diacetate was used as a probe to measure intracellular ROS levels. Data are expressed as mean \pm standard deviation of three independent experiments. ${ }^{*} p<0.05$ and ${ }^{* *} p<0.01$ vs. untreated control group; ${ }^{\#} p<0.05$ and ${ }^{\# \#} p<0.01$ vs. $\mathrm{H}_{2} \mathrm{O}_{2}$ only treated group.

\subsection{Effects of Broccoli Extracts on Cell Viability}

Uncontrolled cell proliferation and evasion of apoptosis are hallmark features of cancer cells [31]. The anti-proliferative effects of broccoli extracts in MCF-7 breast cancer cells, MDA-MB-231 triple-negative breast cancer cells, and MCF-10A normal mammary epithelial cells were assessed using the MTT assay following $48 \mathrm{~h}$ of exposure to broccoli extracts (Figure 5). We observed that cell proliferation was inhibited in breast cancer cells in a dose-dependent manner following exposure to the broccoli extracts (Figure 5). F-S3 and F-M2 showed greater anti-proliferative activities in MCF-7 cells (Figure 5A), while F-M2, H-F, H-M2, and H-M4 showed greater anti-proliferative effects in MDA-MB-231 cells (Figure 5B). The F-F, F-M4, H-F, H-S3, H-M2, and H-M4 extracts exhibited higher $\mathrm{IC}_{50}$ values in MCF-7 cells, whereas F-F, F-S3, and F-M4 had higher IC $_{50}$ levels in MDA-MB-231 cells (Table 2). These results demonstrate that broccoli extracts can inhibit the proliferation of breast cancer cells to varying degrees. Interestingly, broccoli extracts exhibited few cytotoxic effects in normal mammary epithelial cells at the same doses (Table 2, Figure 5C). A recent study by Le at al. (2019) reported in vitro anti-proliferative effects of extracts of broccoli sprouts in lung (A549), liver (HepG2), and colon (Caco-2) cancer cells. Extracts of broccoli sprouts had low cytotoxicity to FL83B normal mouse liver cells [32]. Furthermore, broccoli and collard extracts have been reported to show cytotoxic effects in MCF-7 breast cancer cells at concentrations of 50 and $100 \mathrm{mg} / \mathrm{mL}$ [33]. According to the results of cell proliferation assays, we were unable to find a positive correlation between TPC or TFC and anti-proliferative activities of broccoli extracts. However, the F-S3 and F-M2 extracts, which had high concentrations of L-sulforaphane, exhibited strong cytotoxic effects in MCF-7 breast cancer cells, suggesting a possible relationship between the L-sulforaphane content and cytotoxic activity. 
A

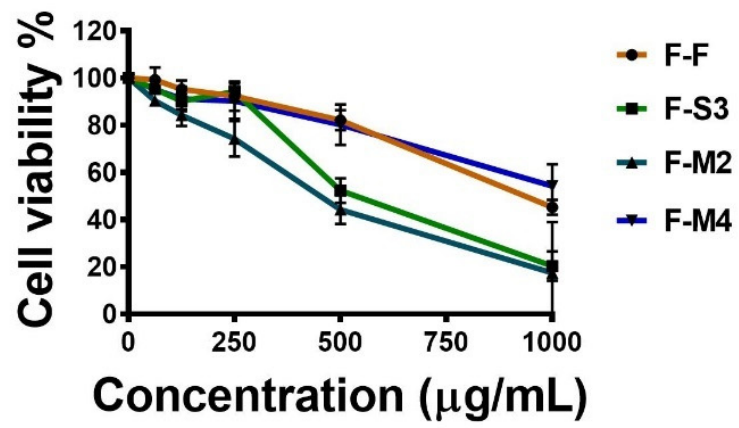

B

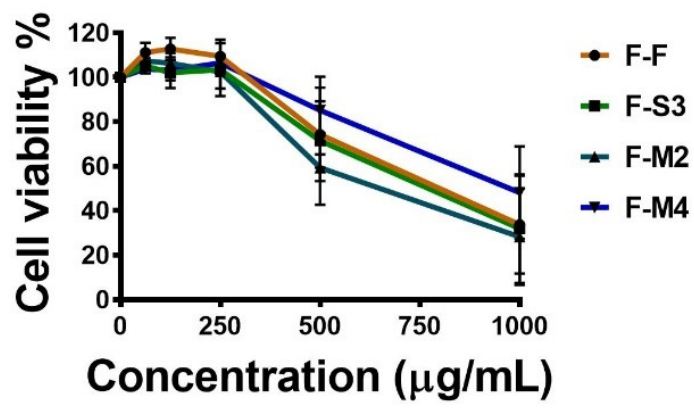

C

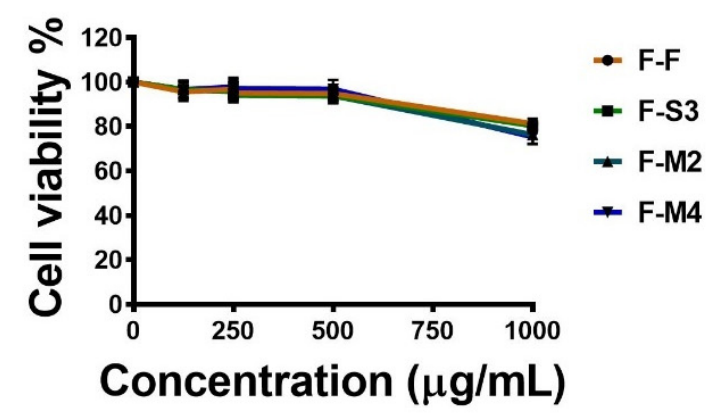

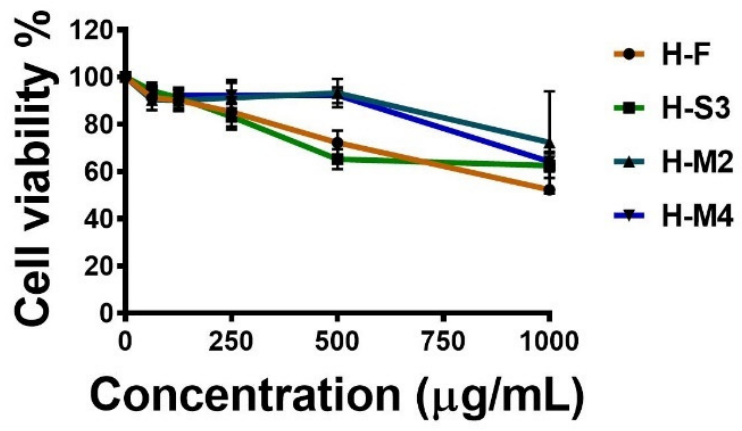

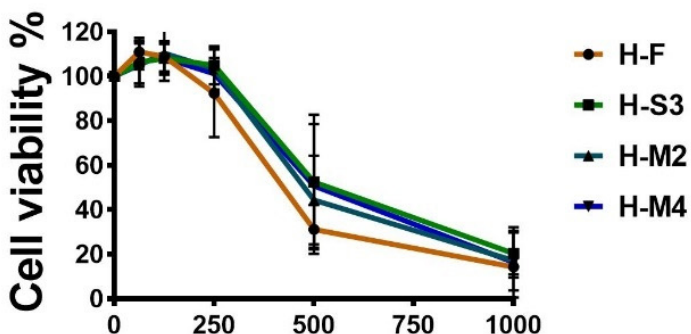

Concentration $(\mu \mathrm{g} / \mathrm{mL})$

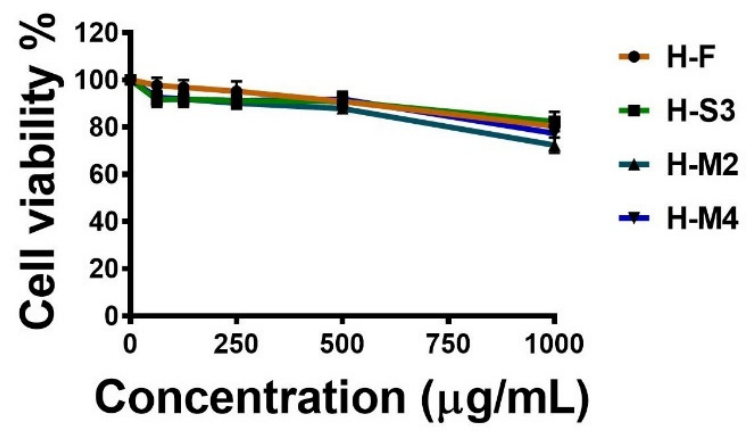

Figure 5. Cytotoxic effects of broccoli extracts (fresh-hot-air-dried (H-F), steamed (3 min)-hot-air-dried (H-S3), microwaved (2 min)-hot-air-dried (H-M2), microwaved (4 min)-hot-air-dried (H-M4), fresh-freeze-dried (F-F), steamed (3 min)-freezedried (F-S3), microwaved (2 min)-freeze-dried (F-M2), and microwaved (4 min)-freeze-dried (F-M4)) in MCF-7 (A), MDAMB-231 (B), and MCF-10A (C) cells as assessed using the MTT assay.

Table 2. $\mathrm{IC}_{50}$ values $(\mu \mathrm{g} / \mathrm{mL})$ of broccoli extracts (F-F, F-S3, F-M2, F-M4, H-F, H-S3, H-M2, and H-M4) in MCF-7 and MDA-MB-231 cells following 48-h exposure as assessed using the MTT assay.

\begin{tabular}{cccccccccc}
\hline $\begin{array}{c}\text { Breast } \\
\text { Cancer Cells }\end{array}$ & F-F & F-S3 & F-M2 & F-M4 & H-F & H-S3 & H-M2 & H-M4 \\
\hline MCF-7 & $1381^{\mathrm{a}}$ & $651^{\mathrm{b}}$ & $447^{\mathrm{c}}$ & $1505.3^{\mathrm{d}}$ & $1195.3^{\mathrm{e}}$ & $1295^{\mathrm{f}}$ & $2988^{\mathrm{g}}$ & $2365^{\mathrm{h}}$ \\
& \pm 10.590 & \pm 17.030 & \pm 4.500 & \pm 3.210 & \pm 54.590 & \pm 55.360 & \pm 10.260 & \pm 15.090 \\
\hline MDA-MB- & $1355^{\mathrm{a}}$ & $1130^{\mathrm{b}}$ & $948^{\mathrm{c}}$ & $1846^{\mathrm{d}}$ & $570^{\mathrm{e}}$ & $820^{\mathrm{f}}$ & $723 \mathrm{~g}$ & $747^{\mathrm{h}}$ \\
231 & \pm 12.500 & \pm 7.780 & \pm 12.100 & \pm 4.200 & \pm 11.410 & \pm 15.140 & \pm 13.410 & \pm 15.470 \\
\hline MCF-10A & $>1000$ & $>1000$ & $>1000$ & $>1000$ & $>1000$ & $>1000$ & $>1000$ & $>1000$ \\
\hline
\end{tabular}

Means with the different letters $(\mathrm{a}-\mathrm{h})$ are significantly different in a row at a $95 \%$ confidence interval. 


\subsection{L-Sulforaphane Quantification in Broccoli Extracts Using HPLC}

Members of the plant family Brassicaceae are rich in secondary metabolites, including glucosinolates and various isothiocyanates $[3,4]$. The enzyme myrosinase, in the glycoside hydrolase family, converts glucosinolates into the corresponding sulforaphanes [3,4]. Various cooking and processing techniques have been reported to affect the conversion rate of glucosinolates into sulforaphanes via enzyme hydrolysis. L-sulforaphane is the biologically active isomer, and has been reported to exert strong antioxidant, anti-inflammatory, anticancer, and chemopreventive effects [34]. Considering the importance of L-sulforaphane as an emerging antioxidant and anti-cancer agent, we quantified L-sulforaphane contents in the broccoli extracts using HPLC. Increased L-sulforaphane concentrations were observed in the F-S3 and F-M2 extracts compared with F-F (Table 3). Hot-air-dried samples exhibited lower L-sulforaphane contents than freeze-dried samples. Among hot-air-dried samples, Lsulforaphane concentrations were reduced relative to $\mathrm{H}-\mathrm{F}$ by steam or microwave treatment (Table 3).

Table 3. Quantification of L-sulforaphane in broccoli extracts (F-F, F-S3, F-M2, F-M4, H-F, H-S3, H-M2, and H-M4) using HPLC.

\begin{tabular}{|c|c|c|c|c|c|c|c|c|}
\hline Component & F-F & F-S3 & F-M2 & F-M4 & H-F & H-S3 & H-M2 & H-M4 \\
\hline L-sulforaphane & $\begin{array}{c}0.11^{\mathrm{a}} \\
\pm 0.001\end{array}$ & $\begin{array}{l}0.18^{\mathrm{b}} \\
\pm 0.001\end{array}$ & $\begin{array}{c}0.38^{c} \\
\pm 0.004\end{array}$ & $\begin{aligned} & 0.003^{\mathrm{d}, \mathrm{i}} \\
\pm & 6.6 \times 10^{-5}\end{aligned}$ & $\begin{array}{l}0.074^{\mathrm{e}} \\
\pm 0.001\end{array}$ & $\begin{array}{c}0.011^{\mathrm{f}} \\
\pm 0.0003\end{array}$ & $\begin{array}{l}0.005^{g, i} \\
\pm 0.0003\end{array}$ & $\begin{array}{c}0.002^{h, i} \\
\pm 3.83 \times \\
10^{-6}\end{array}$ \\
\hline
\end{tabular}

Data are expressed as $\mu \mathrm{g} / \mathrm{g}$ of extract from three independent quantifications. Means with the same letter are not significantly different in a row at $95 \%$ confidence interval.

\section{Conclusions}

In general, steam and microwave treatments increased the TPC of broccoli florets. TFC was reduced following steam treatment, while a slight increase in TFC was observed in microwaved samples. The H-M4 extract exerted stronger radical scavenging effects than other extracts. Furthermore, the H-S3, H-M4, F-S3, and F-M4 extracts showed strong reductions in $\mathrm{H}_{2} \mathrm{O}_{2}$-induced ROS generation. HPLC quantification demonstrated that the F-S3 and F-M2 extracts exhibited elevated levels of L-sulforaphane. In addition, those two extracts showed strong anti-proliferative effects in MCF-7 breast cancer cells.

Although several studies have reported that antioxidant activity is lost during cooking, we did not observe a significant decrease in the antioxidant activity of broccoli following steam and microwave treatments. Therefore, to fully elucidate the antioxidant properties of broccoli after various cooking methods, more research is needed, preferably using cooking and processing methods other than steam and microwave, as well as different extraction methods to isolate total phenolics and flavonoids. As we observed no significant decline in the antioxidant activity of broccoli florets, the cooking and processing methods and conditions used in the present investigation are recommended.

Author Contributions: Conceptualization, H.Y.K., S.K.C. and M.K.E.; methodology, H.Y.K., M.K.E. and K.-H.B.; software, H.Y.K. and M.K.E.; validation, S.K.C., M.K.E. and K.-H.B.; formal analysis, H.Y.K., M.K.E. and K.-H.B.; investigation, S.K.C. and C.S.K.; resources, S.K.C. and C.S.K.; data curation, H.Y.K. and S.K.C.; writing-original draft preparation, M.K.E.; writing-review and editing, M.K.E. and S.K.C.; visualization, S.K.C.; supervision, S.K.C. and C.S.K.; project administration, S.K.C. and C.S.K.; funding acquisition, S.K.C. and C.S.K. All authors have read and agreed to the published version of the manuscript.

Funding: This work was carried out with the support of "Cooperative Research Program for Agriculture Science and Technology Development (Project No. PJ014962012020)", Rural Development Administration, Republic of Korea.

Institutional Review Board Statement: Not applicable.

Informed Consent Statement: Not applicable. 


\section{Data Availability Statement: Not applicable.}

Conflicts of Interest: The authors declare no conflict of interest.

\section{References}

1. Mahn, A.; Rubio, M.P. Evolution of total polyphenols content and antioxidant activity in broccoli florets during storage at different temperatures. J. Food Qual. 2017, 2017, 3742183. [CrossRef]

2. The Food and Agriculture Organization (FAO). Available online: http://www.fao.org/home/en/ (accessed on 18 February 2021).

3. Jeffery, E.H.; Brown, A.F.; Kurilich, A.C.; Keck, A.S.; Matusheski, N.; Klein, B.P.; Juvik, J.A. Variation in content of bioactive components in broccoli. J. Sci. Food Agric. 2003, 16, 323-330. [CrossRef]

4. Vig, A.P.; Rampal, G.; Thind, T.S.; Arora, S. Bio-protective effects of glucosinolates-A review. LWT 2009, 42, 1561-1572. [CrossRef]

5. Tang, G.Y.; Meng, X.; Li, Y.; Zhao, C.N.; Liu, Q.; Li, H.B. Effects of vegetables on cardiovascular diseases and related mechanisms. Nutrients 2017, 9, 857. [CrossRef]

6. Yuan, G.F.; Sun, B.; Yuan, J.; Wang, Q.M. Effects of different cooking methods on health-promoting compounds of broccoli. J. Zhejiang Univ. Sci. B 2009, 10, 580-588. [CrossRef]

7. Xu, Y.; Chen, Y.; Cao, Y.; Xia, W.; Jiang, Q. Application of simultaneous combination of microwave and steam cooking to improve nutritional quality of cooked purple sweet potatoes and saving time. Innov. Food Sci. Emerg. Technol. 2016, 36, 303-310. [CrossRef]

8. Md Salim, N.S.; Gariépy, Y.; Raghavan, V. Hot air drying and microwave-assisted hot air drying of broccoli stalk slices (Brassica oleracea L. Var. Italica). J. Food Process. Preserv. 2017, 41, e12905. [CrossRef]

9. Mahn, A.; Reyes, A. An overview of health-promoting compounds of broccoli (Brassica oleracea var. italica) and the effect of processing. Food Sci. Technol. Int. 2012, 18, 503-514. [CrossRef]

10. Lafarga, T.; Bobo, G.; Viñas, I.; Collazo, C.; Aguiló-Aguayo, I. Effects of thermal and non-thermal processing of cruciferous vegetables on glucosinolates and its derived forms. J. Food Sci. Technol. 2018, 55, 1973-1981. [CrossRef]

11. Amit, S.K.; Uddin, M.M.; Rahman, R.; Islam, S.R.; Khan, M.S. A review on mechanisms and commercial aspects of food preservation and processing. Agric. Food Secur. 2017, 6, 1-22. [CrossRef]

12. Shofian, N.M.; Hamid, A.A.; Osman, A.; Saari, N.; Anwar, F.; Pak Dek, M.S.; Hairuddin, M.R. Effect of freeze-drying on the antioxidant compounds and antioxidant activity of selected tropical fruits. Int. J. Mol. Sci. 2011, 12, 4678-4692. [CrossRef]

13. Ryu, J.Y.; Choi, Y.; Hong, K.H.; Chung, Y.S.; Cho, S.K. Effect of Roasting and Brewing on the Antioxidant and Anti-proliferative Activities of Tartary Buckwheat. Foods 2020, 9, 1331. [CrossRef] [PubMed]

14. Kim, H.; Moon, J.Y.; Kim, H.; Lee, D.S.; Cho, M.; Choi, H.K.; Kim, Y.S.; Mosaddik, A.; Cho, S.K. Antioxidant and anti-proliferative activities of mango (Mangifera indica L.) flesh and peel. Food Chem. 2010, 121, 429-436. [CrossRef]

15. Nguyen, Y.T.K.; Moon, J.Y.; Ediriweera, M.K.; Cho, S.K. Phenethyl isothiocyanate suppresses stemness in the chemo-and radio-resistant triple-negative breast cancer cell line MDA-MB-231/IR via downregulation of metadherin. Cancers 2020, 12, 268. [CrossRef]

16. Ediriweera, M.K.; Tennekoon, K.H.; Samarakoon, S.R.; Thabrew, I.; Dilip De Silva, E. A study of the potential anticancer activity of Mangifera zeylanica bark: Evaluation of cytotoxic and apoptotic effects of the hexane extract and bioassay-guided fractionation to identify phytochemical constituents. Oncol. Lett. 2016, 11, 1335-1344. [CrossRef]

17. Ediriweera, M.K.; Tennekoon, K.H.; Samarakoon, S.R.; Thabrew, I.; De Silva, E.D. Induction of apoptosis in MCF-7 breast cancer cells by Sri Lankan Endemic Mango (Mangifera zeylanica) fruit peel through oxidative stress and analysis of its phytochemical constituents. J. Food Biochem. 2017, 41, e12294. [CrossRef]

18. Samarakoon, S.R.; Shanmuganathan, C.; Ediriweera, M.K.; Piyathilaka, P.; Tennekoon, K.H.; Thabrew, I.; Galhena, P.; De Silva, E.D. Anti-hepatocarcinogenic and anti-oxidant effects of mangrove plant Scyphiphora hydrophyllacea. Pharmacogn. Mag. 2017, 13 (Suppl. 1), S76. [CrossRef]

19. Khanam, U.K.S.; Oba, S.; Yanase, E.; Murakami, Y. Phenolic acids, flavonoids and total antioxidant capacity of selected leafy vegetables. J. Funct. Foods 2012, 4, 979-987. [CrossRef]

20. Turkmen, N.; Sari, F.; Velioglu, Y.S. The effect of cooking methods on total phenolics and antioxidant activity of selected green vegetables. Food Chem. 2005, 93, 713-718. [CrossRef]

21. Gliszczyńska-Świgło, A.; Ciska, E.; Pawlak-Lemańska, K.; Chmielewski, J.; Borkowski, T.; Tyrakowska, B. Changes in the content of health-promoting compounds and antioxidant activity of broccoli after domestic processing. Food Addit. Contam. 2006, 23, 1088-1098. [CrossRef]

22. Şengül, M.; Yildiz, H.; Kavaz, A. The effect of cooking on total polyphenolic content and antioxidant activity of selected vegetables. Int. J. Food Prop. 2014, 17, 481-490. [CrossRef]

23. Dolinsky, M.; Agostinho, C.; Ribeiro, D.; Rocha, G.D.S.; Barroso, S.G.; Ferreira, D.; Fialho, E. Effect of different cooking methods on the polyphenol concentration and antioxidant capacity of selected vegetables. J. Culin. Sci. Technol. 2016, 14, 1-12. [CrossRef]

24. Wu, X.; Zhao, Y.; Haytowitz, D.B.; Chen, P.; Pehrsson, P.R. Effects of domestic cooking on flavonoids in broccoli and calculation of retention factors. Heliyon 2019, 5, e01310. [CrossRef]

25. Erel, O. A novel automated direct measurement method for total antioxidant capacity using a new generation, more stable ABTS radical cation. Clin. Biochem. 2004, 37, 277-285. [CrossRef] [PubMed] 
26. Halpern, H.J.; Spencer, D.P.; van Polen, J.; Bowman, M.K.; Nelson, A.C.; Dowey, E.M.; Teicher, B.A. Imaging radio frequency electron-spin-resonance spectrometer with high resolution and sensitivity for in-vivo measurements. Rev. Sci. Instrum. 1989, 60, 1040-1050. [CrossRef]

27. Ediriweera, M.K.; Tennekoon, K.H.; Samarakoon, S.R.; Adhikari, A.; Thabrew, I.; De Silva, E.D. Isolation of a new resorcinolic lipid from Mangifera zeylanica Hook. f. bark and its cytotoxic and apoptotic potential. Biomed. Pharmacother. 2017, 89, 194-200. [CrossRef] [PubMed]

28. Park, S.K.; Jin, D.E.; Park, C.H.; Seung, T.W.; Choi, S.G.; Heo, H.J. PC12 Cell Protective Effects of Broccoli (Brassica oleracea var. italica) Leaf Fraction against $\mathrm{H}_{2} \mathrm{O}_{2}$-induced Oxidative Stress. Korean J. Food Sci. Technol. 2014, 46, 483-488. [CrossRef]

29. Yang, J.; Song, X.; Feng, Y.; Liu, N.; Fu, Z.; Wu, J.; Yang, L. Natural ingredients-derived antioxidants attenuate $\mathrm{H}_{2} \mathrm{O}_{2}$-induced oxidative stress and have chondroprotective effects on human osteoarthritic chondrocytes via Keap1/Nrf2 pathway. Free Radic. Biol. Med. 2020, 152, 854-864. [CrossRef]

30. Liu, Y.; Liu, P.; Wang, Q.; Sun, F.; Liu, F. Sulforaphane attenuates $\mathrm{H}_{2} \mathrm{O}_{2}$-induced oxidant stress in human trabecular meshwork cells (HTMCs) via the phosphatidylinositol 3-kinase (PI3K)/serine/threonine kinase (Akt)-mediated factor-E2-related factor 2 (Nrf2) signaling activation. Med. Sci. Monit. 2019, 25, 811. [CrossRef] [PubMed]

31. Ediriweera, M.K.; Tennekoon, K.H.; Samarakoon, S.R. In vitro assays and techniques utilized in anticancer drug discovery. J. Appl. Toxicol. 2019, 39, 38-71. [CrossRef]

32. Le, T.N.; Luong, H.Q.; Li, H.P.; Chiu, C.H.; Hsieh, P.C. Broccoli (Brassica oleracea L. var. italica) sprouts as the potential food source for bioactive properties: A comprehensive study on in vitro disease models. Foods 2019, 8, 532. [CrossRef]

33. Radošević, K.; Srček, V.G.; Bubalo, M.C.; Brnčić, S.R.; Takács, K.; Redovniković, I.R. Assessment of glucosinolates, antioxidative and antiproliferative activity of broccoli and collard extracts. J. Food Compos. Anal. 2017, 61, 59-66. [CrossRef]

34. Mazarakis, N.; Snibson, K.; Licciardi, P.V.; Karagiannis, T.C. The potential use of l-sulforaphane for the treatment of chronic inflammatory diseases: A review of the clinical evidence. Clin. Nutr. 2020, 39, 664-675. [CrossRef] 